\title{
CT GUIDED CERVICAL NERVE ROOT INJECTIONS AS A TREATMENT OF ACUTE BRACHALGIA - TECHNIQUE AND MANAGEMENT CONSIDERATIONS FOR RADI- OLOGISTS
}

\author{
Butt S., J Jadun C.K.2
}

he authors describe CT guided injection of cervical nerve roots in treatment of acute arm pain. This technique can help improve the patient's symptoms and, when used with a good clinical support, can effectively reduce the time taken to recover from acute cervical spine spondylotic symptoms. Although the technique remains risky, when used with appropriate precautions, it has good results and an adequate safety record.

1 - The Royal National Orthopaedic Hospital NHS Trust.

2 - University Hospital of North Midlands. Stanmore, UK.

Keywords: cervical spondylosis, acute brachalgia, CT scan, nerve root block.

Corresponding author: Sajid Butt., sajid.butt@rnoh.nhs.uk

For citation: Butt S., Jadun C.K. CT guided cervical nerve root injections as a treatment of acute brachalgia - Technique and management considerations for radiologists. REJR. 2016; 6 (3):54-58. DOI:10.21569/2222-7415-2016-6-3-54-58.

Received: 11.07.2016

Accepted: 25.07.2016

\section{КТ НАВИГАЦИЯ ПРИ АЕЧЕНИИ ОСТРОЙ БРАХИААГИИ С ПОМОЩЬЮ ИНЪЕКЦИЙ В НЕРВНЫЕ КОРЕШКИ ШЕЙНОГО ОТАЕАА ПОЗВОНОЧНИКА - МЕТОАИКА И РЕКОМЕНААЦИИ АЛЯ РЕНТГЕНОЛОГОВ}

\author{
Батт C. ${ }^{1}, \Delta ж а \Delta у н$ C.K.2
}

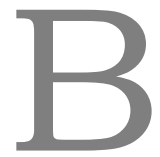

представценной статье описано цечение острой боли в руке с помощью инъекций в нервные корешки шейного отдела позвоночника под контролем компьютерной томографии (КТ). Данный метод мечения позволяет эффективно купировать болевой синдром и способствует быстрой реабилитации пациентов после приступов острой брахиалгии. Несмотря на то, что техника выполнения остается рискованной, при соблюдении определенных мер предосторожности, могут быть достигнуты надлежащий уровень безопасности и удовметворительные результаты мечения.

Ключевые слова: спондилез, шейный отдел позвоночника, острая брахиалгия, КТ, блокада нервного корешка.

Контактный автор: Sajid Butt., sajid.butt@rnoh.nhs.uk

Для иитирования: Батт С., Джадун С.К. КТ навигаиия при лечении острой брахиалгии с помощью инъекиий в нервные корешки шейного отдела позвоночника методика и рекомендащии для рентгенологов. REJR. 2016; 6 (3):54-58. DOI:10.21569/2222-7415-2016-6-3-54-58.

Статья получена: 11.07.2016

Статья принята: 25.07.2016

ervical spondylosis is a common condition and tends to affect middle aged and elderly patients (45 to 64 years age most commonly affected) [1]. Incidence of patients who present with severe pain in one or both arms (brachalgia) is 0.8 per 1000 patients per year [2]. 


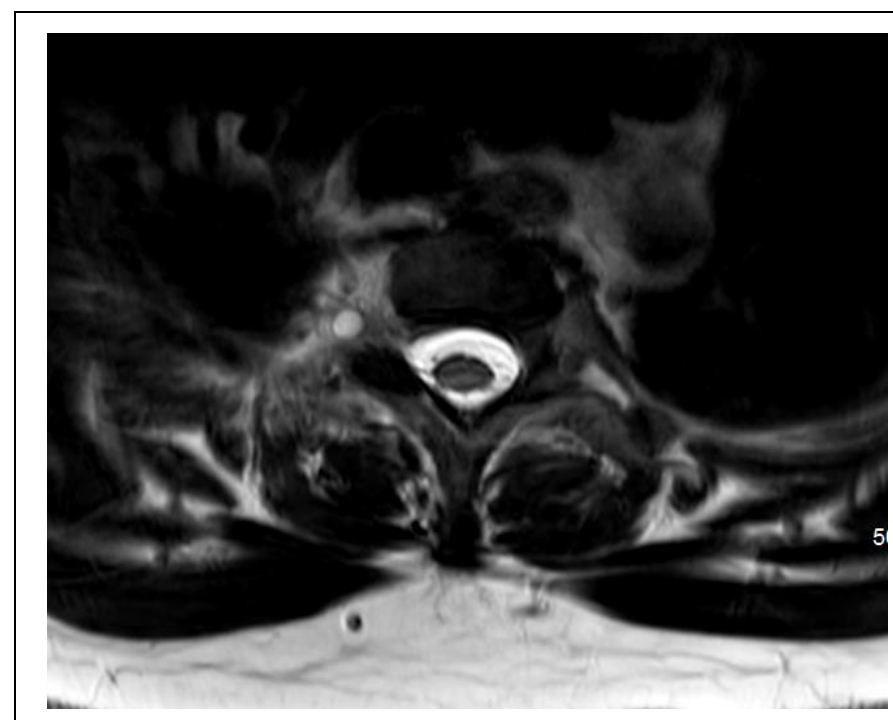

Fig. 1,a.

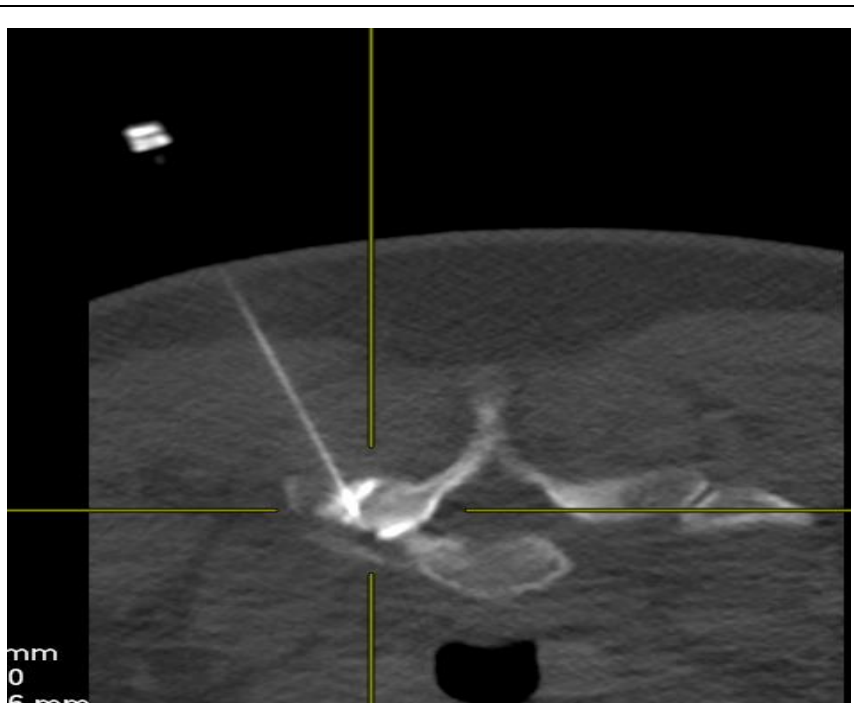

Fig. 1,b.

Fig. 1. MRI, T2-WI. 42 years old female patient who presented with pain in the right arm along C8 nerve root distribution. Her MRI scan showed a posterior perineural cyst at the posterior margin of right C8 nerve root (arrow in figure 1 a).

MSCT, axial projection. This nerve root was injected from a posterior approach with the patient in prone position. Injection of contrast medium shows a perineural spread of the medicine with an intraforaminal spill (arrow).

The pain is usually severe and can be disabling causing the patients to get time off work. According to the data available, neck pain, after low back pain is the commonest musculoskeletal cause for patients to seek advice in primary care worldwide [3].

Most of the patients will respond to conservative treatment including NSAIDs, 3-6 weeks of physiotherapy, cervical collar and rest [4]. In cases which do not respond to these conservative methods and/or in whom the pain is intractable, symptoms can be significantly improved by image guided injections of steroids and local anaesthetic [5]. These injections also have a diagnostic use, when targeted injections can be used to pin point the degree of pain that is being generated by a particular nerve getting compressed [6]. This procedure can be performed under ultrasound, ultrasound and fluoroscopy, fluoroscopy or under CT guidance [7-11].

These injections are however potentially risky and can cause a significant harm by damaging vessels that supply blood to the brain and spinal cord [12-16]. In order for this injection to work, the needle has to be close to the dorsal root ganglion and away from the arterial branches. CT scan allows accurate placement of the treatment needle to be placed in the cervical neural foramen. It is therefore possible to administer the medicine in an effective and safe location [9].

In this article, we describe a technique that has been used in our hospitals for the last ten years with a good degree of efficacy without any significant side effects. The technique is easy to learn and provided the precautions that are mentioned in the paper are adhered to, should not cause any serious harm to the patients.

\section{Patient selection.}

The patients for this procedure are all seen by consultant neurosurgeons. They have MRI scans of cervical spine. These images are seen by a consultant radiologist. Patients' clinical symptoms are correlated by MRI findings. If a discosteophyte bar is seen to cause a nerve root impingement, and the distribution of symptoms correlates with the nerve root compression, along with conservative treatment, the patient is offered to have a $\mathrm{CT}$ guided nerve root block.

At this point, a referral is made to the consultant radiologist who goes through a consent process in which patients are explained about the technique, possible risks vs benefits and post procedure care. Patients are also given written information sheets which allow them to go through the procedural details in their own time.

If the patients' symptoms do not respond to the conservative management, and they decide to proceed with CT guided nerve root block, they get given an appointment for the procedure.

If any patient is on oral anticoagulation treatment, then this is stopped at an appropriate time before the treatment (Warfarin is stopped 5 days before the injection and patients are put on replacement low molecular weight heparin. An- 


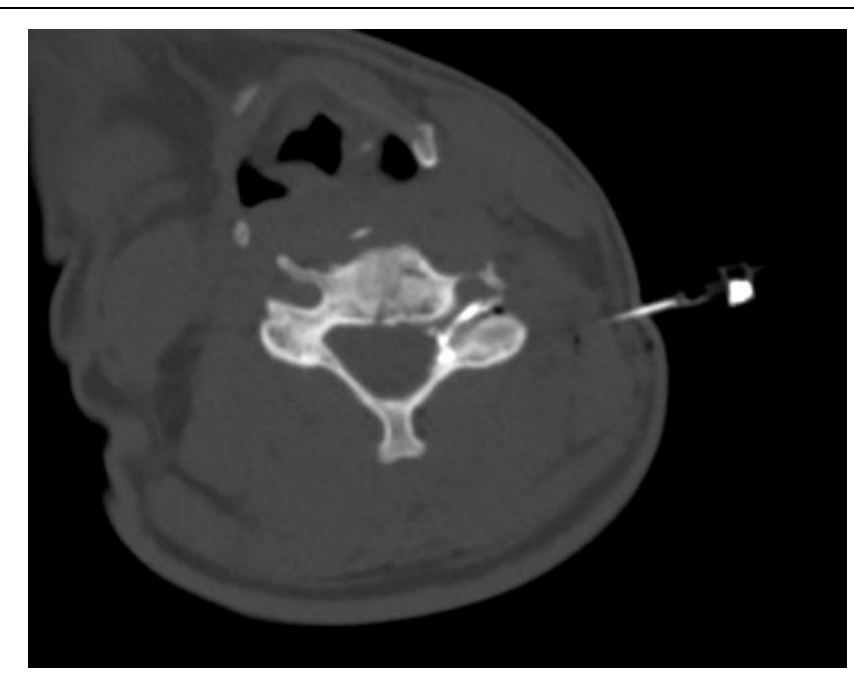

Fig. 2,a.

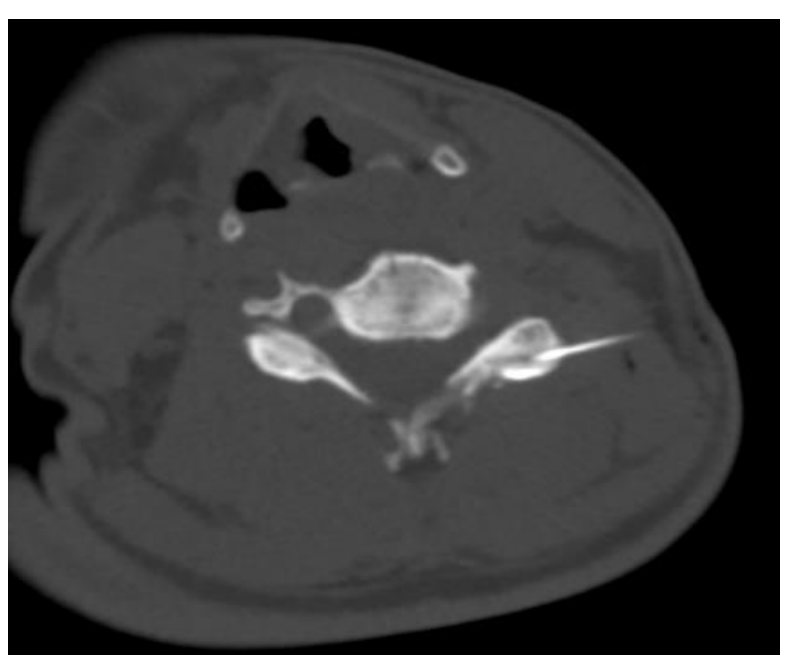

Fig. 2,b.

\section{Fig. 2. MSCT, axial projection.}

When the exiting nerve root is closely applied to the vertebral artery, a safer alternative to direct needle placement at the posterior margin of neural foramen would be to inject the ipsilateral facet joint (figure $2 b)$. Injection of contrast medium shows spill of medicine in intraforaminal distribution (figure 2 a).

tiplatelet medicines are stopped 10 days before the procedure. Aspirin $75 \mathrm{mg}$ can still be used and need not be stopped).

On the day of the procedure, patients report to the in-patient's day ward where they are assessed by the ward staff. They are then sent to the CT scan department where the consultant radiologist, doing the procedure obtains their consent and gets them to sign their consent forms. Getting a two stage consent is important as the procedure is potentially risky. Life threatening and life changing complications have been reported in the world literature following this [11-15]. Giving time to the patients to consider its pros and cons is therefore considered,"good practice".

Patient's relevant imaging is reviewed. It is authors' experience that going through the patient's imaging with them and showing them CT scan images of similar procedures helps them understand the details better and lets them cooperate with the radiologist. It also puts their mind at rest and they are able to tolerate the procedure in a more helpful manner.

\section{Medicines to be used.}

For the injection, a mixture of long acting local anaesthetic and a steroid preparation is used.

Particulate steroids like methyleprednisolone $40 \mathrm{mg}$, (Depo-medrone, Pfizer, Sandwich, UK) and Kenalog (Triamcinolone acetate $40 \mathrm{mg}$, Squibb, Uxbridge UK) tend to stay around the injection site for a longer period of time. These steroid preparations are however risky as the particulate material could get injected in the small vessels and result in embolic injury to spinal cord and brain [14].

The final needle position is next to the dorsal root ganglion of the exiting spinal nerve. The spinal nerve exits from the neural foramen in its lower half. In the upper half, there are small blood vessels. Anteriorly, there is the vertebral artery. The needle therefore is to be positioned adjacent to the posterior margin of the lower half of the neural foramen [17]. With CT scan guidance, it is possible to avoid position of the needle within the wall of the vertebral artery. However, the smaller unnamed branches of blood vessels are not visible with CT scan resolution, and therefore it is possible, theoretically at least, that some of the injection material gets into these vessels. It is this infiltration of particulate material in these vessels which has been hypothesised to cause embolic injury to the spinal cord in some case reports [16, $18,19]$. Therefore, the general consensus is that the steroid preparation that is used should be non-particulate. Recommended steroid preparation to be used is betamethasone $(8 \mathrm{mg}$, Betamethasone $4 \mathrm{mg} / \mathrm{ml}$ solution, Focus pharmaceuticals, London, UK) [20]. This steroid injection would tend to get absorbed relatively quickly, and would not have a longer pain relief as injection of particulate material steroid, but the difference in the

degree and duration of pain relief was not found to be clinically significant [21]. The soluble steroid preparations are however certainly safer to use [20].

The local anaesthetic with which this steroid is mixed is $0.5 \%$ Bupivacaine (Bupivacaine $0.5 \% \mathrm{w} / \mathrm{v}$ injection, Accord healthcare Ltd. Har- 


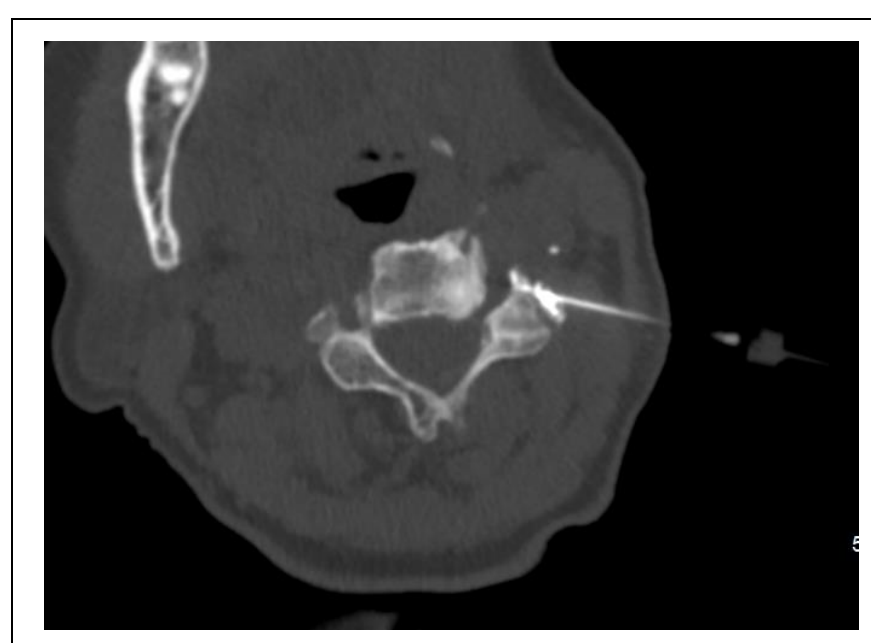

Fig. 3.

\section{Fig. 3. MSCT, axial projection.}

The needle is placed at the posterior margin of neural foramen. Injection of contrast medium shows a peineural spread of medicine with no arterial flow.

row, UK).

\section{Technique.}

Patient is positioned supine on the CT scan table. For injecting C7-T1 neural foramen, a prone position can also be used (Fig. 1 b). In patients in whom the neural foramen is markedly narrowed and where the vertebral artery is closely apposed with the nerve root, needle tip can be aimed for its tip to be positioned in the facet joint (Fig. 2 a, b). Injection of contrast medium shows that most of these patients would have medicine spread in extradural distribution in the neural foramen.

For supine position, patient's head is slightly turned to the contra lateral side and a marking grid is placed on the skin.

A short segment CT scan of the section of neck is performed. The appropriate CT scan image is chosen and a skin mark is placed to help identifying the spot which would allow access to the peri neural needle placement (Fig. 3).

Skin is cleansed with $0.5 \%$ Chlorhexidine solution in $70 \%$ alcohol (Hydrex solution, Ecolab Ltd. Leeds UK). Chlorhexidine in alcohol is superior to Chlorhexidine in water or Povidone iodine solution. Because of neuroirritant nature of chlorhexidine, $2 \%$ solution of this compound (Chlora Prep, Carefusion, UK Ltd. Reigate UK) is best avoided [21]. The area is draped and local anaesthetic (1\% Lidocaine, Hameln pharmaceuticals, Gloucester UK) is injected in the subcutaneous plain.

Steroid and levo-Bupivacaine is then mixed up in a $3 \mathrm{mls}$ luer lock syringe. Omnipaque 250 contrast medium is drawn up in a second $3 \mathrm{mls}$ luer lock syringe. This syringe is clearly marked with a sticker for its accurate identification and is connected with a long plastic tube. While these syringes are being prepared, local anaesthetic that has been injected in the subcutaneous plain has anaesthetised the soft tissues. A needle localising scan is then obtained which confirms the line of needle advancement.

A $20 \mathrm{G} 5 \mathrm{~cm}$ long needle is used for actual injection. This is slowly and incrementally advanced. Each incremental advancement is followed by a CT scan image to confirm that the line of advancement of needle is accurate.

Once the desired needle tip position has been achieved (at the posterior margin of the lower half of the neural foramen abutting the anterior surface of the articular pillar), the needle is connected with the plastic tube which was connected with the syringe that has been filled up with contrast medium.

The plunger is withdrawn to ensure that no blood is being aspirated. If there is blood seen in the tube, the needle tip is readjusted. A small amount of contrast medium is then injected. CT scan image confirms that the needle tip is correct ly placed and ideally should show some contrast medium spreading medially, in an intraforaminal direction (Fig. 3). Once this has been confirmed, the syringe containing contrast medium is changed with the syringe containing the mixture of steroids and local anaesthetic. This is then slowly injected. The patient is warned that they could feel some tingling or pain extending along the distribution of the nerve. Once the injection is complete, the needle is taken out of patient's neck and the injection site is cleaned off iodine and an antiseptic dressing applied. table.

The patient is gently taken off the CT scan

They are then kept in the department for around 30 minutes. They are allowed to leave once they have been confirmed to be stable. They get given a pain recording chart on which they record their pain score for the next two weeks.

\section{Post Operative Complications.}

Some patients feel tingling along the distribution of the nerve which can also be mildly painful. Some patients feel a bit dizzy. We have seen the following findings in a minority of patients:

Temporary arm weakness, vasovagal dizziness, horner's syndrome, allergic rash and some worsening of arm pain. These features are all temporary and do not last for more than a couple of days responding to conservative management. The more serious reported complications include stroke and ischemic damage to the spinal cord. We have not seen these complications in any of our patients.

\section{Conclusion.}

The technique described is not difficult to learn. This however remains a risky procedure. All 


\section{RUSSIAN ELECTRONIC JOURNAL OF RADIOLOGY}

due diligence needs to be taken in order to minimise the risks. These risks are rare, nonetheless, remain serious. By using the technique described, pain relief can be provided to these patients which can make a significant improvement in their

\section{References:}

1.Radhakrishnan K., Litchy W.J., O'Fallon W.M., Kurland L.T. Epidemiology of cervical radiculopathy. A population-based study from Rochester, Minnesota, 1976 through 1990. Brain: a journal of neurology. 1994; 117 (2): 325-35.

2.Ellenberg M.R., Honet J.C., Treanor W.J. Cervical radiculopathy. Archives of physical medicine and rehabilitation. 1994; 75 (3): 342-52.

3.Binder A.I. Cervical spondylosis and neck pain. BMJ (Clinical research ed). 2007; 334 (7592): 527-31.

4.Kuijper B., Tans J.T., Beelen A., Nollet F., de Visser M. Cervical collar or physiotherapy versus wait and see policy for recent onset cervical radiculopathy: randomised trial. BMJ (Clinical research ed). 2009; 339: b3883.

5.Boswell M.V., Shah R.V., Everett C.R., Sehgal N., McKenzie Brown A.M., Abdi S., et al. Interventional techniques in the management of chronic spinal pain: evidence-based practice guidelines. Pain physician. 2005; 8 (1): 1-47.

6.Leonardi M., Pfirrmann C.W., Boos N. Injection studies in spinal disorders. Clinical orthopaedics and related research. 2006; 443: 168-82.

7.Wakeling C., Bateman A., Hatrick A., Chatakondu S. Combined fluoroscopic and ultrasound guided cervical nerve root injections. International orthopaedics. 2016.

8.Jee H., Lee J.H., Kim J., Park K.D., Lee W.Y., Park Y. Ultrasound-guided selective nerve root block versus fluoroscopyguided transforaminal block for the treatment of radicular pain in the lower cervical spine: a randomized, blinded, controlled study. Skeletal radiology. 2013; 42 (1): 69-78.

9.Bensler S., Sutter R., Pfirrmann C.W., Peterson C.K. Long Term Outcomes from CT-guided Indirect Cervical Nerve Root Blocks and their relationship to the MRI findings--A prospective Study. European radiology. 2015; 25 (11): 3405-13.

10.Berger O., Dousset V., Delmer O., Pointillart V., Vital J.M., Caille J.M. [Evaluation of the efficacy of foraminal infusions of corticosteroids guided by computed tomography in the treatment of radicular pain by foraminal injection]. Journal de radiologie. 1999; 80 (9): 917-25.

11.Manchikanti L., Falco F.J., Diwan S., Hirsch J.A., Smith H.S. Cervical radicular pain: the role of interlaminar and transforaminal epidural injections. Current pain and headache reports. 2014; 18 (1): 389. quality of life. Diagnostic information obtained can also be crucial to confirm the relevance of MRI findings of nerve root compression which helps in planning of surgical procedures.

12.Baker R., Dreyfuss P., Mercer S., Bogduk N. Cervical transforaminal injection of corticosteroids into a radicular artery: a possible mechanism for spinal cord injury. Pain. 2003; 103 (1-2): 211-5.

13.Brouwers P.J., Kottink E.J., Simon M.A., Prevo R.L. A cervical anterior spinal artery syndrome after diagnostic blockade of the right C6-nerve root. Pain. 2001; 91 (3): 397-9.

14.Feeley I.H., Healy E.F., Noel J., Kiely P.J., Murphy T.M. Particulate and non-particulate steroids in spinal epidurals: a systematic review and meta-analysis. European spine journal : official publication of the European Spine Society, the European Spinal Deformity Society, and the European Section of the Cervical Spine Research Society. 2016.

15.Furman M.B., Giovanniello M.T., O'Brien E.M. Incidence of intravascular penetration in transforaminal cervical epidural steroid injections. Spine. 2003; 28 (1): 21-5.

16.Hodler J., Boos N., Schubert M. Must we discontinue selective cervical nerve root blocks? Report of two cases and review of the literature. European spine journal : official publication of the European Spine Society, the European Spinal Deformity Society, and the European Section of the Cervical Spine Research Society. 2013; 22 Suppl 3: S466-70.

17.Vallee J.N., Feydy A., Carlier R.Y., Mutschler C., Mompoint D., Vallee C.A. Chronic cervical radiculopathy: lateral-approach periradicular corticosteroid injection. Radiology. 2001; 218 (3): 886-92.

18.Huston C.W., Slipman C.W., Garvin C. Complications and side effects of cervical and lumbosacral selective nerve root injections. Archives of physical medicine and rehabilitation. 2005; 86 (2): 277-83.

19.Manchikanti L., Hirsch J.A. Neurological complications associated with epidural steroid injections. Current pain and headache reports. 2015; 19 (5): 482.

20.Benzon H.T., Chew T.L., McCarthy R.J., Benzon H.A., Walega D.R. Comparison of the particle sizes of different steroids and the effect of dilution: a review of the relative neurotoxicities of the steroids. Anesthesiology. 2007; 106 (2): 331-8.

21.Working P. Campbell J.P., Plaat F., Checketts M.R., Bogod D., Tighe S. et al. Safety guideline: skin antisepsis for central neuraxial blockade. Anaesthesia. 2014; 69 (11): 1279-86. 